\title{
UJI TOKSISITAS AKUT DAN LD50 EKSTRAK ETANOL DAUN KIRINYUH (Euphatorium odoratum Linn) PADA MENCIT (Mus musculus)
}

\author{
Jumain*), Syahruni $^{* *)}$, Farid F.T ${ }^{* *)}$ \\ *) Jurusan Farmasi Poltekkes Kemenkes Makassar \\ **) Jurusan Farmasi Universitas Pancasakti Makassar
}

\begin{abstract}
ABSTRAK
Telah dilakukan penelitian tentang Uji Toksisitas Akut dan $\mathrm{LD}_{50}$ Ekstrak Etanol Daun Kirinyuh (Euphatorium odoratum Linn) Pada Mencit (Mus musculus.Penelitian ini bertujuan untuk mengetahui nilai Lethal Dosis $50\left(\mathrm{LD}_{50}\right)$ atau dosis dari ekstrak etanol daun kirinyuh yang dapat membunuh 50\% mencit (Mus musculus), sehingga dapat memberikan data dasar keamanan dosis dari daun kirinyuh yang dapat digunakan. Dalam penelitian ini menggunakan metode perhitungan Reed dan Muench, yang menggunakan 30 ekor mencit masing-masing 15 ekor betina dan jantan yang dibagi menjadi 5 kelompok perlakuan, masing-masing terdiri atas 6 ekor mencit 3 ekor betina dan 3 ekor jantan. Kelompok I NaCMC 1\% sebagai Kontrol, Kelompok II diberi ekstrak etanol daun kirinyuh dengan dosis $10 \% \mathrm{~b} / \mathrm{v}$. Kelompok III diberi ekstrak etanol daun kirinyuh dengan dosis $20 \% \mathrm{~b} / \mathrm{v}$. Kelompok IV diberi ekstrak etanol daun kirinyuh dengan dosis $40 \% \mathrm{~b} / \mathrm{v}$, sedangkan untuk Kelompok V diberikan dosis tertinggi $80 \% \mathrm{~b} / \mathrm{v}$ pada mencit. Sediaan uji diberikan secara oral dengan hanya satu kali pemberian pada awal masa penelitian. Gejala toksik yang dominan yaitu parasimpatomimetik (diare dan urinasi). Hasil penelitian yang didapatkan Nilai $\mathrm{LD}_{50}$ yang diperoleh dari hasil pengujian toksisitas akut ekstrak etanol daun kirinyuh (Euphatorium odoratum Linn) yaitu sebesar $14,1416 \mathrm{~g} / \mathrm{Kg} \mathrm{BB}$ atau $28,82 \%$ ekstrak dan termasuk dalam kategori "Toksik Ringan".
\end{abstract}

Kata kunci : Daun Kirinyuh (Euphatorium odoratum Linn), Ekstrak kental, Toksisitas akut, LD50

\section{PENDAHULUAN}

Penggunaan obat tradisional dalam upaya mempertahankan kesehatan masyarakat telah lama kita ketahui. Bahkan sampai saat ini $80 \%$ penduduk dunia masih menggantungkan dirinya pada pengobatan tradisional. Seperempat dari obat - obat modern yang beredar di dunia berasal dari bahan aktif yang diisolasi dan dikembangkan dari tanaman. Obat tradisional adalah bahan atau ramuan bahan yang berupa tumbuhan, bahan hewan, bahan mineral, sediaan cairan (galenik) atau campuran dari bahan tersebut yang secara turun temurun telah digunakan untuk pengobatan dan dapat diterapkan sesuai dengan norma yang berlaku dimasyarakat (Badan Pengawas Obat dan Makanan Republik Indonesia, 2014).

Meskipun obat tradisional sudah dimanfaatkan sejak lama namun tidak sepenuhnya aman, karena obat tradisional merupakan senyawa asing bagi tubuh, sehingga sangatlah penting mengetahui potensi ketoksikannya. Efek toksik pada makhluk hidup dapat terlihat dan dapat juga tidak bila dosis yang diserap relatif kecil kerusakannya dapat terbatas pada sel saja (Eriadi, A., Dkk, 2016). Salah satu tumbuhan yang biasa digunakan sebagai bahan obat adalah daun kirinyuh (Eupatorium odoratum Linn) tumbuhan ini oleh masyarakat wilayah makassar digunakan sebagai obat luka dan antioksidan (Fitrah, M., 2016).

Daun kirinyuh (Eupatorium odoratum Linn) merupakan salah satu jenis tumbuhan dari famili asteraceae. Daunnya mengandung beberapa senyawa utama seperti tannin, fenol, flavonoid, saponin dan steroid. Minyak essensial dari daunnya memiliki kandungan $\alpha$-pinene, cadinene, camphora, limonene, $\beta$-caryophyllene dan candinol isomer (Rahman, A., 2017).

Secara tradisional daun kirinyuh digunakan sebagai obat dalam penyembuhan luka, obat kumur untuk pengobatan sakit pada tenggorokan, obat batuk, obat malaria, antimikroba, sakit kepala, astringent, 
antispasmodik, antihipertensi dan anti inflamasi.

Pada penelitian sebelumnya telah dilakukan pengujian terhadap efek inflamasi ekstrak etanol daun kirinyuh secara topikal dapat memberikan efek antiinflamasi dan mempengaruhi jumlah sel leukosit terhadap mencit putih jantan (Ifora, Dkk., 2017) juga telah dilakukan pengujian terhadap ekstrak etanol daun kirinyuh untuk pengobatan luka pada mencit jantan, kontrol dan pembanding, hasilnya menunjukkan bahwa ekstrak etanol daun kirinyuh memberikan efek penyembuhan luka yang lebih cepat pada konsentrasi 10\% (Yenti, 2011) dan ekstrak daun kirinyuh mempunyai aktivitas antiproliferasi terhadap sel leukemia L1210 (Fitrah, M.,2016)

Uji toksisitas dibedakan menjadi uji toksisitas akut, subkronik, dan kronik. Uji toksisitas akut dirancang untuk menentukkan Lethal dose atau disingkat $\mathrm{LD}_{50}$ suatu zat. Uji toksisitas akut dilakukan dengan memberikan zat kimia yang sedang diuji sebanyak satu kali, atau beberapa kali dalam jangka waktu 24 jam. Uji toksisitas akut merupakan uji pra klinik yang bertujuan mengukur derajat efek toksik suatu senyawa dalam waktu tertentu setelah pemberian dosis tunggal. Tolak ukur kuantitatif yang sering digunakan untuk menyatakan kisaran dosis letal pada uji toksisitas akut adalah $\mathrm{LD}_{50}$, Tanaman obat harus melalui berbagai proses uji untuk keamanan konsumsinya, salah satunya uji toksisitas akut (Syamsul, E.S., Dkk., 2015). Mengingat betapa luasnya pemakaian daun kirinyuh ini sebagai obat, maka penggunaan tanaman ini harus melalui serangkaian uji, seperti uji khasiat, toksisitas dan uji klinik. Dengan dasar tersebut dan mempertimbangkan potensinya yang cukup tinggi, maka penulis tertarik untuk melakukan uji toksisitas akut dan $\mathrm{LD}_{50}$ ekstrak etanol daun kirinyuh (Euphatorium odoratum Linn) pada mencit (Mus musculus) .

\section{Rumusan Masalah}

1. Gejala toksik yang dominan terjadi setelah pemberian ekstrak etanol daun kirinyuh ( Euphatorium odoratum Linn.) ?

2. Berapakah $\mathrm{LD}_{50}$ ekstrak etanol daun kirinyuh (Euphatorium odoratum Linn) pada mencit dan apa kategori toksisitas ekstrak daun kirinyuh (Euphatorium odoratum Linn) pada mencit (Mus musculus)?

\section{Tujuan Penelitian}

1. Tujuan Umum

Penelitian ini bertujaun untuk mengetahui efek toksisitas ekstrak etanol daun kirinyuh (Euphatorium odoratum Linn) pada mencit yang diukur secara kuantitatif dengan $\mathrm{LD}_{50}$.

2. Tujuan Khusus

a. Mengamati gejala - gejala pemberian ekstrak etanol daun kirinyuh (Eupatorium odoratum Linn) dalam 24 jam pertama untuk mengetahui gejala toksik yang dominan.

b. Menentukan nilai dosis ekstrak etanol daun kirinyuh (Euphatorium odoratum Linn) yang mengakibatkan kematian $50 \%$ populasi mencit dan untuk mengetahui kategori toksisitas akut ekstrak daun kirinyuh (Euphatorium odoratum Linn) pada mencit yang diukur dengan $\mathrm{LD}_{50}$.

\section{METODE DAN BAHAN}

\section{Alat dan Bahan}

Alat - alat yang diperlukan dalam penelitian ini adalah kandang mencit, timbangan analitik, Sonde lambung, Kapas, gelas erlenmeyer, kompor, pinset, batang pengaduk, baskom, sendok tanduk, Alat untuk membuat bahan uji ekstrak etanol daun kirinyuh.

Bahan - bahan yang diperlukan dalam penelitian ini adalah Ekstrak etanol daun kirinyuh, Mencit putih, aquadest, NaCMC, Makanan dan minuman mencit.

\section{Tempat dan Waktu Penelitian}

Penelitian ini dilaksanakan di Laboratorium Farmakologi Jurusan Farmasi Poltekkes Kemenkes Makassar pada tanggal 24 November 2017 selama 14 hari.

\section{Populasi dan Sampel}

Populasi penelitian ini adalah mencit berbadan sehat dengan bobot tidak kurang 20 gram. Sedangkan Penentuan besar sampel menurut ketentuan WHO, yakni dengan jumlah sampel minimal 5 
untuk setiap kelompok perlakuan. Penelitian ini menggunakan 30 ekor mencit yaitu 15 ekor betina dan 15 ekor jantan yang dibagi dalam 5 kelompok, tiap kelompok 6 ekor mencit ( 3 ekor betina dan 3 ekor jantan).

\section{Teknik Pengumpulan Data}

Data yang dikumpulkan dalam penelitian ini adalah data primer dari hasil pengamatan hewan coba kelompok perlakuan, Data yang diperoleh berupa data kuantitatif dan kualitatif. Data kuantitif yang akan diperoleh yaitu jumlah hewan coba yang mati, sedangkan data kualitatif yang akan diperoleh berupa gejala efek toksik suatu senyawa (ekstrak daun kirinyuh) terhadap hewan coba.

\section{Pengambilan dan pengolahan bahan uji}

a. Pengambilan bahan uji

Bahan yang digunakan adalah tumbuhan daun kirinyuh (Euphatorium odoratum Linn) bagian yang diambil adalah daunnya yang segar yang didapatkan di daerah bolalohe desa Tebba kecamatan Salomekko kabupaten Bone.

b. Pengolahan bahan uji

Daun yang dipetik dicuci bersih kemudian dipotong kecil-kecil, dikeringkan dengan cara dianginanginkan dan tidak terkena cahaya.

c. Ekstraksi bahan uji

Metode ekstraksi yang digunakan dalam penelitian ini yaitu maserasi. daun kirinyuh (Euphatorium odoratum Linn) ditimbang sebanyak 500 gram kemudian dimasukkan dalam wadah maserasi. Ditambahkan pelarut etanol $70 \%$

\section{Prosedur Uji Toksisitas Akut pada Mencit}

a. Pembuatan larutan Koloidal Na. CMC $1 \%$ b/v sebanyak $200 \mathrm{ml}$ Sebanyak 2 gram serbuk Na. CMC kemudian dipanaskan air sebanyak $200 \mathrm{ml}$ hingga mendidh lalu dimasukkan serbuk Na.CMC, diaduk hingga terbentuk larutan koloid jernih dengan menggunkan pengaduk.

b. Pemilihan dan penyiapan sampel Sampel yang digunakan dalam penelitian ini adalah mencit (Mus musculus). Berbadan sehat dengan bobot tidak kurang 20 gram. Jumlah mencit yang digunakan adalah 30 ekor (15 ekor betina dan 15 ekor jantan) dibagi 5 kelompok dan masing-masing kelompok terdiri dari 6 ekor (3 ekor betina dan 3 ekor jantan). Sebelum mendapat perlakuan mengalami masa adaptasi dan diberi ransum pakan standard dan minum selama 7 hari.

c. Perlakuan Terhadap Sampel

Pada penelitian ini, 30 ekor mencit dibagi dalam 5 kelompok perlakuan yang masing - masing terdiri dari 6 ekor mencit yang ditentukan secara acak. Sebelum diberi perlakuan masing-masing mencit ditimbang. Lima kelompok perlakuan tersebut adalah :

1) Kelompok I : kontrol ( $\mathrm{NaCMC}$ $1 \%$ )

2) Kelompok II : diberi ekstrak daun kirinyuh dengan dosis $10 \% \mathrm{~b} / \mathrm{v}$

3) Kelompok III : diberi ekstrak daun kirinyuh dengan dosis $20 \%$ $\mathrm{b} / \mathrm{v}$

4) Kelompok IV : diberi ekstrak daun kirinyuh dengan dosis $40 \%$ $\mathrm{b} / \mathrm{v}$

5) Kelompok V : diberi ekstrak daun kirinyuh dengan dosis $80 \% \mathrm{~b} / \mathrm{v}$

Pemberian ekstrak daun

kirinyuh (Euphatorium odoratum) pada mencit dilakukan melalui sonde lambung dan hanya diberikan satu kali, yaitu pada hari ke- 8 .

d. Penentuan Nilai LD $_{50}$ dan Pengamatan Gejala Toksik Yang Menyertai

Sebelum dilakukan pengamatan sampel diamati sebelum diberi perlakuan. Hal ini bertujuan untuk mengetahui perubahan gejala yang terjadi setelah diberi perlakuan dengan membandingkan gejala atau perilaku sebelum perlakuan. Nilai $\mathrm{LD}_{50}$ ditentukan dengan menghitung jumlah kematian sampel selama 24 jam yang disebabkan oleh pemberian tunggal sediaan uji pada kelompok mencit dengan dosis $10 \% \mathrm{~b} / \mathrm{v}, 20 \%$ b/v, $40 \%$ b/v dan $80 \%$ b/v. Hewan uji dikelompokkan secara acak menjadi 5 kelompok yang masingmasing kelompok terdiri dari 6 ekor 
mencit (3 ekor betina dan 3 ekor jantan). Masing-masing kelompok perlakuan diberikan secara oral dengan suspensi ekstrak etanol daun kirinyuh (Euphatorium odoratum Linn) dengan dosis dosis $10 \% \mathrm{~b} / \mathrm{v}$, $20 \% \mathrm{~b} / \mathrm{v}, 40 \% \mathrm{~b} / \mathrm{v}$ dan $80 \%$ b/v. Pengamatan gejala klinis dilakukan 24 jam pertama setelah perlakuan. Penghitungan sampel dilakukan sejak perlakuan hingga 24 jam berikutnya. Sementara itu, setelah pemberian dilakukan pengamatan gejala-gejala toksik yang menyertai.

\section{Analisa Data}

Data yang dikumpulkan dalam penelitian ini adalah data primer dari hasil pengamatan hewan coba, baik kelompok kontrol maupun kelompok perlakuan. Data yang diperoleh berupa data kuantitatif dan kualitatif. Data kuantitif yang akan diperoleh yaitu jumlah hewan coba yang mati. Data $\mathrm{LD}_{50}$ diambil dari jumlah mencit yang mati dan yang masih hidup pada setiap kelompok. Selanjutnya dihitung nilai $\mathrm{LD}_{50}$ menggunakan Metode Aritmatik Reed dan Muench.

\section{HASIL DAN PEMBAHASAN}

\section{Hasil Penelitian}

1. Ekstraksi Daun Kirinyuh (Eupatorium Odoratum Linn)

Tabel 1. Hasil Ekstraksi Daun Kirinyuh (Eupatorium odoratum Linn)

\begin{tabular}{ccccc}
\hline Sampel & Berat sampel & Berat Ekstrak & $\begin{array}{c}\text { Volume Pelarut } \\
(\text { Etanol 70\% })\end{array}$ & $\begin{array}{c}\text { Lama } \\
\text { perendaman }\end{array}$ \\
\hline Daun Kirinyuh & 500 gram & 56 gram & 5 liter & $5 \times 24$ jam \\
\hline
\end{tabular}

2. Hasil pengamatan uji kuantitatif

Hasil penelitian setelah pemberian Ekstrak Etanol Daun Kirinyuh secara oral pada mencit adalah sebagai berikut.

Tabel 2. Hasil pengamatan jumlah mencit yang mati dan hidup setelah pemberian Ekstrak Etanol Daun Kirinyuh.

\begin{tabular}{cccc}
\hline $\begin{array}{c}\text { Konsentrasi sediaan } \\
(\% \mathbf{b} / \mathbf{v})\end{array}$ & $\begin{array}{c}\text { Jumlah } \\
\text { Mencit }\end{array}$ & \multicolumn{2}{c}{ Jumlah Mencit } \\
\cline { 3 - 4 } Kontrol & 6 & 0 & Mati \\
$10 \% \mathrm{~b} / \mathrm{v}$ & 6 & 1 & 6 \\
$20 \% \mathrm{~b} / \mathrm{v}$ & 6 & 2 & 5 \\
$40 \% \mathrm{~b} / \mathrm{v}$ & 6 & 4 & 2 \\
$80 \% \mathrm{~b} / \mathrm{v}$ & 6 & 5 & 1 \\
\hline Jumlah & 30 & 12 & 18 \\
\hline
\end{tabular}

Tabel 5. Hasil pengamatan jumlah mencit yang mati berdasarkan perbedaan jenis kelamin setelah pemberian Ekstrak Etanol Daun Kirinyuh

\begin{tabular}{|c|c|c|c|c|c|c|}
\hline \multirow{3}{*}{$\begin{array}{c}\text { Konsentrasi } \\
\text { sediaan }(\% \text { b/v) }\end{array}$} & \multirow{2}{*}{\multicolumn{2}{|c|}{ Sampel (Mencit) }} & \multicolumn{4}{|c|}{ Seteleh Perlakuan } \\
\hline & & & \multicolumn{2}{|c|}{ Betina } & \multicolumn{2}{|c|}{ Jantan } \\
\hline & Betina & Jantan & Hidup & Mati & Hidup & Mati \\
\hline Kontrol & 3 & 3 & 3 & - & 3 & - \\
\hline $10 \%$ & 3 & 3 & 2 & 1 & 3 & - \\
\hline $20 \%$ & 3 & 3 & 2 & 1 & 2 & 1 \\
\hline $40 \%$ & 3 & 3 & 1 & 2 & 1 & 2 \\
\hline $80 \%$ & 3 & 3 & 1 & 2 & - & 3 \\
\hline Jumlah & 15 & 15 & 9 & 6 & 9 & 6 \\
\hline
\end{tabular}

Gejalah toksik yang diperlihatkan yaitu salivasi, urinaria, diare, kejang-kejang, diuretik, laju napas cepat, penurun aktivitas gerak, dan kehilangan daya cengkram dan kelumpuhan. 


\section{Pembahasan}

Penelitian dilakukan dengan menggunakan 30 ekor mencit (15 ekor betina dan 15 ekor jantan) yang sebelumnya telah diaklimatisasi selama 1 minggu yang bertujuan untuk mengkondisikan sampel dengan suasana laboratorium dan untuk menghilangkan stress akibat transportasi, sampel dibagi menjadi 5 kelompok yaitu 1 kelompok sebagai kontrol, dan 4 kelompok yang diberi perlakuan yaitu kelompok 1 diberi Na-CMC 1\% dan kelompok perlakuan 2, 3, 4, 5, diberi ekstrak etanol daun kirinyuh berturut-turut $10 \% \mathrm{~b} / \mathrm{v}, 20 \% \mathrm{~b} / \mathrm{v}, 40 \% \mathrm{~b} / \mathrm{v}$ dan $80 \%$ b/v (dalam $20 \mathrm{ml}$ ).

Pada proses maserasi yang dilakukan dengan simplisia daun kirinyuh dengan berat sampel 500 gr, dengan menggunakan pelarut etanol $70 \%$ selama $5 \mathrm{x}$ 24 jam, diperoleh sebanyak 56 gram ekstrak etanol daun kirinyuh.

Pemberian ekstrak daun kirinyuh (Euphatorium odoratum Linn) pada mencit dilakukan secara oral melalui sonde lambung dan hanya diberikan satu kali, yaitu pada hari pertama. Diberi bahan uji sesuai dengan dosis tiap kelompok. Pengamatan gejala toksik dan mencit yang mati dan dilanjutkan sampai 7 hari.

Hasil penelitian ini menunjukkan bahwa pemberian ekstrak daun kirinyuh (Euphatorium Odoratum Linn) yang diamati dari hari pertama sampai hari ke 7 diperoleh data kematian berdasarkan Tabel 5, kematian mencit dimulai dari dosis terbesar yaitu $80 \%$ dimana terdapat 5 ekor mencit yang mati, dosis $40 \%$ terdapat 4 ekor mencit yang mati dan dosis $20 \%$ terdapat 2 ekor mencit yang mati, jadi pada hari pertama terdapat 11 ekor mencit yang mati, ada beberapa kemungkinan mencit tersebut mati dalam penelitian, yang pertama bisa disebabkan oleh stress yang dapat menurunkan sistem imun, dimana stress ini mempengaruhi sistem imun tubuh melalui stimulasi sekresi kortisol dan adrenalin serta berpengaruh terhadap pelepasan noradrenalin dan postganglion simpatik terminal saraf dipembuluh darah dan organ lymfoid. Sedangkan yang kedua bisa disebabkan karena tingginya dosis yang diberikan terhadap mencit sehingga terjadi efek toksisitas terhadap mencit yang mengakibatkan kematian. Pada hari keempat terdapat 1 mencit yang mati dengan pemberian dosis $10 \%$ sedangkan untuk sisa mencit lainnya, tetap dilakukan pengamatan sampai pada hari ke 7. Jangka waktu pengamatan harus cukup lama sehingga adanya efek toksik yang terlambat atau tertunda, termasuk kematian tidak terlewati dalam pengamatan, berdasarkan alasan diatas maka pengamatan dilakukan selama 7 hari.

Pemberian ekstrak etanol daun kirinyuh secara oral menyebabkan zat aktif yang terdapat dalam ekstrak daun kirinyuh diabsorbsi dalam saluran pencernaan. Zat aktif kemudian mengalami proses distribusi dan metabolisme. Produk metabolisme yang bersifat toksik bekerja sebagai inhibitor enzim untuk tahap metabolisme selanjutnya, reaksi antar zat aktif dengan reseptor dalam organ efektor menyebabkan timbulnya gejala keracunan. Setiap sampel yang digunakan akan memberikan respon yang berbeda pada dosis tertentu. Perbedaan respon tersebut diakibatkan oleh perbedaan tingkat kepekaan setiap sampel.

Gejala keracunan/toksik yang timbul setelah pemberian ekstrak daun kirinyuh secara oral pada mencit dengan konsentrasi $10 \%, 20 \%$, 40\%, dan $80 \%$ b/v memberikan gejala-gejala yang timbul adalah urine berlebihan, diare, melompatlompat, laju nafas cepat, kejang-kejang, penurunan aktìvitas gerak, lesu, kehilangan daya cengkram, salivasi dan kelumpuhan setelah beberapa waktu yang dibandingkan dengan kontrol.

Gejala toksik berupa urinasi dan diare terjadi setelah mencit diberi ekstrak etanol daun kirinyuh pada semua konsentrasi. Gejala ini timbul karena adanya perangsangan pada saraf parasimpatis. Perangsangan pada saraf parasimpatis dapat menyebabkan stimulasi aktivitas pencernaan yaitu meningkatkan peristaltik usus dan sekresi getah lambung. Efek lain sebagai akibat perangsangan saraf parasimpatis adalah terjadinya kontraksi kandung kemih dan ureter dengan efek memperlancar keluarnya air seni.

Efek penurunan aktivitas gerak, laju nafas cepat dan kehilangan daya cengkram pada konsentrasi $10 \%$ belum teramati, tetapi teramati pada konsentrasi $20 \%, 40 \%$ dan $80 \%$. Sedangkan kelumpuhan dan salivasi pada konsentrasi $10 \%, 20 \%$, belum teramati, tetapi pada konsentrasi $40 \%$ 
dan $80 \%$ baru teramati, setelah beberapa waktu mencit mengalami kematian.

Gejala keracunan dari ekstrak daun kirinyuh yang dominan adalah parasimpatomimetik atau perangsangan saraf parasimpatis. Gejala ini terjadi karena adanya stimulasi aktivasi saluran pencernaan dan peristaltik usus yang menyebabkan diare, menstimulasi kontraksi kandung kemih dengan ureter yang berefek memperlancar keluarnya air seni (urinasi), dan menstimulasi susunan saraf pusat yang berefek kejang- kejang.

Nilai LD $_{50}$ ekstrak daun kirinyuh berdasarkan hasil pengamatan terhadap jumlah kematian mencit setelah pemberian ekstrak daun kirinyuh menunjukkan bahwa dengan konsentrasi $10 \%, 20 \%, 40 \%$, dan $80 \%$ dapat menyebabkan kematian pada mencit. Jumlah kematian mencit tinggi dimana 5 mencit mati pada konsentrasi $80 \%$ b/v dalam waktu 7 hari. Terjadinya kematian mencit diawali dengan gejala-gejala toksik berupa pengeluaran urin, dan diare yang berlebihan, selanjutnya adanya penurunan aktivitas gerak, kelumpuhan, kejang-kejang, salivasi hingga terjadi kematian.

Penentuan $\mathrm{LD}_{50}$ dengan metode Reed dan Muench, menggunakan nilai kumulatif yang mengasumsikan bahwa mencit yang mati dengan dosis tertentu akan memberikan nilai $\mathrm{LD}_{50}$ diantara dosis yang lebih besar dari $50 \%$ dan dosis yang lebih kecil dari 50\%. Berdasarkan perhitungan dengan metode ini diperoleh nilai $\mathrm{LD}_{50}$ adalah $14,1416 \mathrm{~g}$ ekstrak/kg berat badan mencit atau 28,28\% ekstrak. Berdasarkan klasifikasi toksisitas menurut Priyanto termasuk dalam kategori "Toksik Ringan" dimana toksik ringan memiliki range $5-15$ $\mathrm{g} / \mathrm{Kg} \mathrm{BB}$, secara umum semakin kecil nilai $\mathrm{LD}_{50}$ semakin toksik senyawa tersebut, begitu pula sebaliknya semakin besar nilai $\mathrm{LD}_{50}$ semakin rendah toksisitasnya.

\section{PENUTUP}

\section{Kesimpulan}

Berdasarkan hasil analisis data dan pembahasan setelah dilakukan penelitian dan pengamatan maka dapat disìmpulkan bahwa :

1. Gejala toksik yang dominan yaitu parasimpatomimetik (diare, urinasi).

2. Nilai $\mathrm{LD}_{50}$ yang diperoleh dari hasil pengujian toksisitas akut ekstrak etanol daun kirinyuh (Euphatorium Odoratum Linn) menggunakan metode Reed dan Muench yaitu sebesar 14,1416 g/Kg BB atau $28,82 \%$ ekstrak dan termasuk dalam kategori "toksik ringan".

\section{Saran}

Disarankan untuk melakukan penelitian lebih lanjut mengenai uji toksisitas dengan menggunakan metode yang berbeda, dan perlu dilakukan pengujian toksisitas subkronik dan kronik untuk mengetahui dampak yang ditimbulkan akibat pemberian ekstrak etanol daun kirinyuh (Euphatorium odoratum Linn) agar didapatkan informasi lebih mendalam sehingga dapat dijadikan sebagai acuan untuk penelitian selanjutnya.

\section{DAFTAR PUSTAKA}

Ansel, C Howard. 2008. Pengantar Bentuk Sediaan Farmasi. Universitas indonesia press.

Badan Pengawas Obat dan Makanan Republik Indonesia. 2014. Peraturan Kepala Badan Pengawas Obat dan Makanan Republik Indonesia Nomor 12 Tahun 2014 tentang Persyaratan mutu obat tradisional. Jakarta : Badan Pengawas Obat dan Makanan.

College of Agricultural Science. 2006. Toxicity of Pesticides. The Pennsylvania State University.

Depkes RI, 2000, Materia Medika Indonesia, Edisi 5, 120-123, Departemen Kesehatan Indonesia, Jakarta.

Dirjen POM. 2000. Sediaan Galenik, Edisi II. Jakarta: Departemen Kesehatan RI Bhakti Husada.

Donatus, I.A. 2005. Toksikologi Dasar. Laboratorium Farmakologi dan Toksikologi. Fakultas Farmasi. UGM. Yogyakarta

Eriadi, A., Dkk., 2016. Uji Toksisitas Akut Ekstrak Etanol Daun Kirinyuh (Chromolaenodorata (L) R.M.King \& H. Rob) Pada Mencit Putih Jantan. Jurnal Farmasi Higea, Vol. 
8, No. 2. Fakultas Farmasi Universitas Andalas Padang

Ernest, H., 2005. A Textbook of Modern Toxicology. 3rd Edition. New York: John Wiley and Sons Inc.

Ernst, Steven, Dkk. 2015. Principles of Translational Science in Medicine "Pharmaceutical Toxicology". Updated from 1st edition, former authors: Ernst $\mathrm{S}$ (corresponding), Boyer S, \& Platz S.

Fatimatuzzahra, F., 2013. Uji Toksisitas Akut Ekstrk Etanol Daun Kemangi (Ocimum canum Sims) Terhadap Larva Artemia Salina Leach Dengan Metode Brine Shrimp Lethality Test (BSLT). Skripsi. Program Studi Pendidikan Dokter Fakultas Kedokteran dan Ilmu Kesehatan Universitas Islam Negeri Syarif Hidayatullah. Jakarta

Fitrah, M., 2016. Identifikasi Ekstrak Daun Kopasanda (Chromolaena odorata Linn) Terhadap Sel Antiproliferasi Tikus Leukemia L1210. Jurnal Farmasi FIK UINAM Vol.4 No.3, Jurusan Farmasi Fakultas Kedokteran dan Ilmu Kesehatan Universitas Islam Negeri Alauddin Makassar

Ifora, Dkk., 2017. Efek Antiinflamasi Krim Ekstrak Etanol Daun Kirinyuh (Chromolaena odorata (L) R.M. King \& H. Rob ) Secara Topikal Dan Penentuan Jumlah Sel Leukosit Pada Mencit Putih Jantan. Jurnal Farmasi Higea, Vol. 9, No. 1, Fakultas Farmasi Universitas Andalas Padang

Malole, M. B. M dan Pramono, C. S. U., 1989. Penggunaan Hewan-Hewan Percobaan Di Laboratorium. Departemen Pendidikan dan Kebudayaan. Direktorat Jenderal Pendidikan Tinggi Pusat Antar Universitas Biotekologi IPB. Bogor.

Meyna,s dkk.2010. Analisis Hayati. Majalah Ilmu Kefarmasian. Vol.1.
Priyanto. 2010.Toksikologi Ed: 2. Depok: Leskonfi Lembaga Studi dan Konsultasi Farmakologi.

Rahman, A., 2017. Efek Salep Ekstrak Daun Kirinyuh (Euphatorium odaratum) Terhadap Penyembuhan Luka Sayat Pada Ayam Petelur (Gallus leghorn). Skripsi. Program Studi Kedokteran Hewan Fakultas Kedokteran Universitas Hasanuddin. Makassar

Robinson, T, 1995., Kandungan Organik Tumbuhan Tinggi, Edisi VI, ITB, Bandung.

Setiawati, W., Dkk., 2008. Tumbuhan Bahan Pestisida Nabati dan Cara Pembuatannya untuk Pengendalian Organisme Pengganggu Tumbuhan $(O P T)$. Balai Penelitian Tanaman Sayuran. Bandung

Syam, A.K., 2016. Uji Toksisitass Akut Ekstrak Etanol Daun Kayu Hitam (Diospyros celebica B.) Terhadap Mencit (Mus musculus). Skripsi. Fakultas Kedokteran dan Ilmu Kesehatan Universitas Islam Negeri Alauddin Makassar. Makassar

Syamsudin. 2011. Farmakologi Eksperimental: Buku Ajar. Penerbit Universitas Indonesia. Jakarta.

Syamsul, E.S., Dkk., 2015. Uji Toksisitas Akut Ekstrak Etanol Daun Kerehau (Callicarpa longifolia Lam.) Terhadap Mencit Putih. Jurnal Imiah Manuntung. Akademi Farmasi Samarinda.

Soewolo. 2010. Pengantar anatomi Fisiologi Hewan. Dirjen Dikti Depdiknas. Jakarta.

Tjitrosoepomo, G., 2010. Taksonomi Tumbuhan (Schizophyta) Cet. 10. Gadjah Mada University Presc. Yogyakarta

Vital, P.G., and W.L, Rivera, 2009. Antimicrobacterial activity and citoxicity of Chromolaena odorata (L.f) King and Robinson and Uncaria perrottetii (A. rich) Merr. Extracts, Available online at http://www.academicjournals.org/ 
